\title{
Estimasi Nilai Percepatan Tanah Maksimum Provinsi Aceh Berdasarkan Data Gempa Segmen Tripa Tahun 1976 - 2016 Dengan Menggunakan Rumusan Mcguire
}

\author{
Rido Nofaslah", Dwi Pujiastuti \\ Laboratorium Fisika Bumi, Jurusan Fisika, FMIPA, Universitas Andalas \\ Kampus Unand, Limau Manis, Padang, 25163 \\ ridonofaslah@yahoo.co.id
}

\begin{abstract}
ABSTRAK
Telah dilakukan estimasi nilai percepatan tanah maksimum provinsi Aceh berdasarkan data gempa Segmen Tripa tahun 1976 - 2016 menggunakan rumusan McGuire. Data gempa yang digunakan diperoleh dari United States Geological Survey (USGS) dengan magnitudo $\geq 3$ SR dan kedalaman $\leq 70$ $\mathrm{km}$. Daerah penelitian dibatasi $1,67^{\circ} \mathrm{LU}-5,67^{\circ} \mathrm{LU}$ dan $94,53^{\circ} \mathrm{BT}-98,53^{\circ}$ BT yang dibagi atas gridgrid berukuran $0,5^{\circ}$ sehingga didapatkan 90 titik penghitungan. Data gempa yang diperoleh sebanyak 34 data tersebar pada daerah $3,20^{\circ} \mathrm{LU}-4,45^{\circ} \mathrm{LU}$ dan $96,50^{\circ} \mathrm{BT}-97,91^{\circ} \mathrm{BT}$. Dari hasil pengolahan data didapatkan peta Peak Ground Acceleration (PGA) dan intensitas gempa. Nilai PGA terkecil yaitu 17 $\mathrm{cm} / \mathrm{s}^{2}$ terdapat di kabupaten Aceh Jaya dan nilai PGA terbesar yaitu $112 \mathrm{~cm} / \mathrm{s}^{2}$ terdapat di kabupaten Aceh Tenggara. Intensitas gempa yang dihasilkan berkisar antara III - VI MMI.

Kata kunci: gempa bumi, grid, intensitas, MMI, PGA, Segmen Tripa
\end{abstract}

\section{ABSTRACT}

An estimation of peak ground acceleration values estimated in Aceh province based on earthquake data in the Tripa Segment by using McGuire empirical formulas has been performed. Data obtained from United States Geological Survey (USGS) with magnitude $\geq 3$ SR and depth $\leq 70 \mathrm{~km}$. Research area is restricted in $1,67^{\circ} \mathrm{LU}-5,67^{\circ} \mathrm{LU}$ dan $94,53^{\circ} \mathrm{BT}-98,53^{\circ} \mathrm{BT}$ that is devided into grids $0.5^{\circ}$ in sizes, so 90 points obtained for calculation. There are 34 earthquake data in the $3,20^{\circ} \mathrm{LU}-4,45^{\circ} \mathrm{LU}$ and $96,50^{\circ} \mathrm{BT}$ - 97,91 BT. The result shows map of Peak Ground Acceleration (PGA) and intensity. Aceh Jaya has the smallest $P G A$ value is $17 \mathrm{~cm} / \mathrm{s}^{2}$ and Southeast Aceh has the highest $P G A$ value is $112 \mathrm{~cm} / \mathrm{s}^{2}$. The intensity of earthquakes ranges between III - VI MMI.

Keywords:earthquake, grid, intensity, MMI, PGA,Tripa Segment

\section{PENDAHULUAN}

Indonesia merupakan suatu wilayah yang memiliki aktivitas kegempaan yang sangat tinggi. Hal ini karena Indonesia terletak pada pertemuan tiga lempeng tektonik utama. Ketiga lempeng tektonik utama tersebut adalah Lempeng Indo-Australia, Lempeng Eurasia dan Lempeng Pasifik. Lempeng Indo-Australia bergerak menyusup ke bawah Lempeng Eurasia ke arah Utara dengan kecepatan 50-70 mm/tahun di sepanjang palung laut Sumatera, Jawa, Bali dan Lombok. Sedangkan Lempeng Pasifik bergerak dengan kecepatan $\pm 120 \mathrm{~mm} /$ tahun ke arah Barat menumbuk tepian Utara Papua dan Timur Sulawesi (Natawidjaja, 2007).

Berdasarkan pergerakan relatif antar lempeng, kondisi seismisitas dan mekanisme sumber gempa, maka zona gempa Indonesia diklasifikasikan menjadi 3 bagian yaitu zona subduksi, zona transformasi dan zona divergen. Tatanan tektonik Sumatera dipengaruhi oleh zona subduksi yang membentang sepanjang $\pm 1.200 \mathrm{~km}$ ( Latief, 2003) dan zona transformasi yang ditandai dengan sesar-sesar aktif di sepanjang pulau Sumatera.

Pulau Sumatera merupakan kawasan seismic gap. Kawasan ini memiliki tektonik aktif dan pernah mengalami gempa besar, kemudian bersifat pasif atau sangat jarang mengalami gempa besar dalam jangka waktu yang lama. Daerah yang memiliki kawasan seismic gap berpotensi memiliki gempa bumi dengan energi yang sangat besar (Delfebriyadi, 2010). Salah satu kawasan seismic gap di wilayah Sumatera terdapat di segmen Simeulue (LIPI, 2010).

Selain zona subduksi, sumber gempa di wilayah Aceh juga berasal dari tiga segmen sesar yang berada di sesar Sumatera, yaitu segmen Aceh dengan panjang $200 \mathrm{~km}$, segmen Seulimeum dengan panjang $120 \mathrm{~km}$ dan segmen Tripa dengan panjang $180 \mathrm{~km}$ (Sieh dan Natawidjaja, dkk., 2000). Sekitar 100 tahun yang lalu telah terjadi gempa besar di zona sesar ini terutama segmen Tripa pada tahun 1936 (Aceh Tenggara) sebesar 7,2 SR dan tahun 1990 di Gayo Luas dengan kekuatan 6,8 SR (Simanjuntak, 2014). 
Setiap gempa yang terjadi akan menimbulkan satu nilai percepatan tanah pada suatu tempat. Nilai percepatan tanah yang akan diperhitungkan dalam perencanaan bangunan adalah percepatan tanah maksimum. Nilai ini akan menunjukkan resiko kerusakan yang akan ditimbulkan terhadap bangunan. Nilai percepatan tanah sangat dibutuhkan untuk menyesuaikan kekuatan bangunan yang akan dibangun pada daerah tersebut (Sunarjo,dkk., 2012). Pengukuran nilai percepatan tanah dapat dilakukan dengan menggunakan alat pengukur akselerograf dan pendekatan secara empiris. Penempatan akselerograf pada beberapa titik tertentu saja akan menghasilkan pengukuran tanah hanya pada daerah tertentu juga. Sedangkan pendekatan secara empiris dapat memberikan gambaran secara umum untuk percepatan tanah maksimum sesuai titik yang dibutuhkan (Ibrahim dan Subardjo, 2003). Nilai percepatan tanah dapat dihitung dengan menggunakan pendekatan dari data historis gempa bumi, yaitu hubungan rumus Richter, hubungan rumus Murphy dan O'Brein, hubungan rumus Donovan dan hubungan rumus Esteva. Selain itu dengan menghubungkan besarnya magnitudo dengan faktor lain beberapa rumusan empiris yang digunakan adalah rumusan Donovan, McGuire R.K, Joyner dan Boore, $\mathrm{Si}$ and Midorikawa dan sebagainya. Setiap rumusan memiliki karakteristik tersendiri berdasarkan daerah yang diteliti.

Rumusan McGuire telah digunakan sebelumnya untuk menentukan nilai percepatan tanah provinsi Sumatera Barat oleh Marlisa, dkk., (2015). Dari hasil penentuan nilai percepatan tanah didapatkan wilayah yang paling rentan terhadap kerusakan gempa adalah wilayah Tanah Datar. Pada penelitian ini akan dilakukan estimasi percepatan tanah maksimum provinsi Aceh dengan historis gempa tahun 1976 sampai 2016 dengan menggunakan rumusan McGuire untuk segmen Tripa.

\section{METODE}

\subsection{Teknik Penelitian}

Penentuan nilai percepatan tanah maksimum Provinsi Aceh berdasarkan gempa yang berasal dari Segmen Simeulue yang merupakan zona subduksi dan Segmen Tripa yang merupakan zona transform. Rumusan yang digunakan adalah McGuire. Penelitian ini dilakukan dengan tahap - tahap sebagai berikut :

1. Mengumpulkan data sekunder gempa bumi. Data yang digunakan adalah data gempa dari tahun 1976 sampai 2016 dengan magnitudo $\geq 3$ SR dengan kedalaman $\leq 70 \mathrm{~km}$ serta dibatasi wilayah $1,67{ }^{\circ} \mathrm{LU}-5,67^{\circ} \mathrm{LU}$ dan $94,53{ }^{\circ} \mathrm{BT}-98,53{ }^{\circ} \mathrm{BT}$. Data ini didapatkan dari situs United States Geological Survey (USGS).

2. Membagi daerah penelitian dengan jarak $0,5^{\circ}$ seperti yang dapat dilihat pada Gambar 1 .

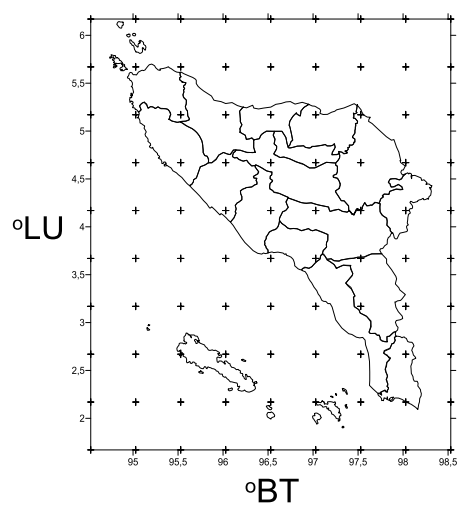

Gambar 1 Grid Provinsi Aceh

3. Menghitung jarak antara koordinat episenter ke masing - masing koordinat daerah perhitungan, sehingga diperoleh jarak episenter.

Jarak episenter dapat diketahui dengan menggunakan Persamaan (1) :

$$
\Delta^{2}=\left(x_{2}-x_{1}\right)^{2}+\left(y_{2}-y_{1}\right)^{2}
$$


$x_{l}$ merupakan lintang daerah perhitungan $\left(^{\circ}\right), y_{l}$ merupakan bujur daerah perhitungan $\left(^{\circ}\right), x_{2}$ merupakan lintang episenter gempa $\left(^{\circ}\right)$, dan $y_{2}$ merupakan bujur episenter gempa $\left(^{\circ}\right)$. Nilai yang didapat dijadikan koordinat episenter dalam $\mathrm{km}$ dengan $1^{\circ}=111 \mathrm{~km}$.

4. Menghitung jarak hiposenter dengan Persamaan (2):

$$
R^{2}=\Delta^{2}+h^{2}
$$

$R$ merupakan jarak hiposenter $(\mathrm{km}), \Delta$ merupakan jarak episenter $(\mathrm{km})$, dan $h$ merupakan kedalaman $(\mathrm{km})$.

5. Menghitung nilai percepatan tanah maksimum dengan menggunakan rumus empiris McGuire (Persamaan 3) untuk segmen Tripa di setiap titik grid.

$$
\alpha=(472,3) \times 10^{0,278 M} \times(R+25)^{-1,301}
$$

$\alpha$ merupakan peak ground acceleration $\left(\mathrm{gal}, \mathrm{cm} / \mathrm{s}^{2}\right), M$ merupakan magnitudo permukaan, dan $R$ merupakan jarak hiposenter $(\mathrm{km})$.

6. Menentukan nilai maksimum percepatan tanah dari setiap titik.

7. Mengkonversi nilai Peak Ground Acceleration (PGA) ke skala Modified Mercalli Intensity (MMI), untuk menunjukkan skala intensitas dengan menggunakan rumusan empiris Murphy \& O’Brien pada Persamaan 4.

$$
M M I=2,86 \log (P G A)+1,24
$$

dengan MMI adalah skala intensitas dan PGA adalah Peak Ground Acceleration (gal).

8. Membuat peta Aceh denggan menggunakan software Arc View Gis 3.3.

9. Membuat peta percepatan tanah maksimum dan intensitas provinsi Aceh dengan menggunakan software Surfer.

10. Menganalisis nilai dan intensitas percepatan tanah maksimum (Peak Ground Acceleration) provinsi Aceh dari pemetaan yang telah dilakukan.

\section{HASIL DAN DISKUSI}

\subsection{Percepatan Tanah Maksimum Provinsi Aceh dengan Episenter Segmen Tripa}

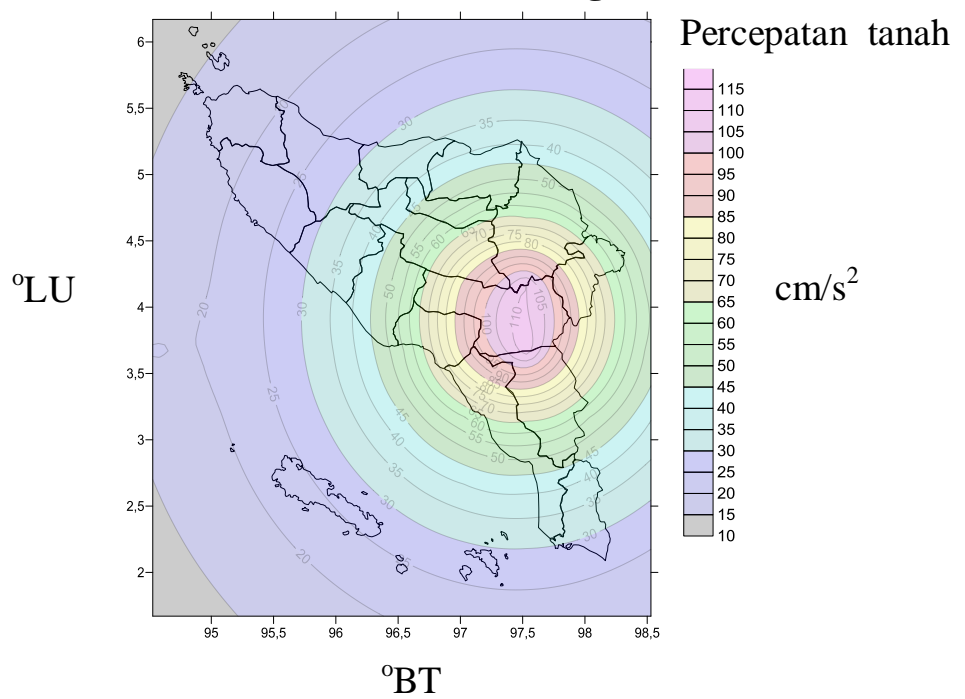

Gambar 2 Percepatan Tanah Maksimum Provinsi Aceh dengan Episenter Segmen Tripa

Berdasarkan Gambar 2 dapat dilihat nilai percepatan tanah maksimum terbesar provinsi Aceh dengan episenter Segmen Tripa adalah Kabupaten Aceh Tenggara sebesar $112 \mathrm{~cm} / \mathrm{s}^{2}$. Sedangkan Kabupaten Aceh Singkil, Kabupaten Simeulue, Kabupaten Aceh Tenggara, Kabupaten Aceh Barat Daya, Kabupaten Aceh Barat, Kabupaten Nagan Raya, Kabupaten Aceh Tamiang, Kabupaten Aceh Tengah, Kabupaten Bener Meriah, Kabupaten Aceh Timur, Kabupaten Aceh Besar, Kabupaten Pidie, Kabupaten Bireun dan Kabupaten Aceh Utara 
memiliki nilai percepatan tanah maksimum yang berkisar antara $21 \mathrm{~cm} / \mathrm{s}^{2}$ sampai $110 \mathrm{~cm} / \mathrm{s}^{2}$. Untuk nilai percepatan tanah maksimum terkecil terdapat pada Kabupaten Aceh Jaya sebesar 17 $\mathrm{cm} / \mathrm{s}^{2}$.

\subsection{Intensitas Gempa Provinsi Aceh dengan Episenter Segmen Tripa}

Pada Gambar 3 dapat dilihat intensitas gempa provinsi Aceh. Diantaranya adalah Kabupaten Aceh Singkil, Kabupaten Simeulue, Kabupaten Aceh Barat Daya, Kabupaten Aceh Barat, Kabupaten Nagan Raya, Kabupaten Aceh Jaya, Kabupaten Aceh Tengah, Kabupaten Bener Meriah, Kabupaten Aceh Timur, Kabupaten Aceh Tamiang, Kabupaten Aceh Besar, Kabupaten Pidie, Kabupaten Bireun dan Kabupaten Aceh Utara dengan skala MMI III - V. Gejala yang ditimbulkan berupa gempa yang dapat dirasakan namun tidak menimbulkan kerusakan. Benda-benda yang digantung bergoyang dan jendela kaca akan bergetar. Sedangkan Kabupaten Aceh Tenggara dan Kabupaten Gayo Lues memiliki skala MMI VI dengan gejala kerusakan ringan. Gejala yang ditimbulkan berupa bangunan mengalami kerusakan ringan seperti retak dan sebagian genteng berjatuhan.

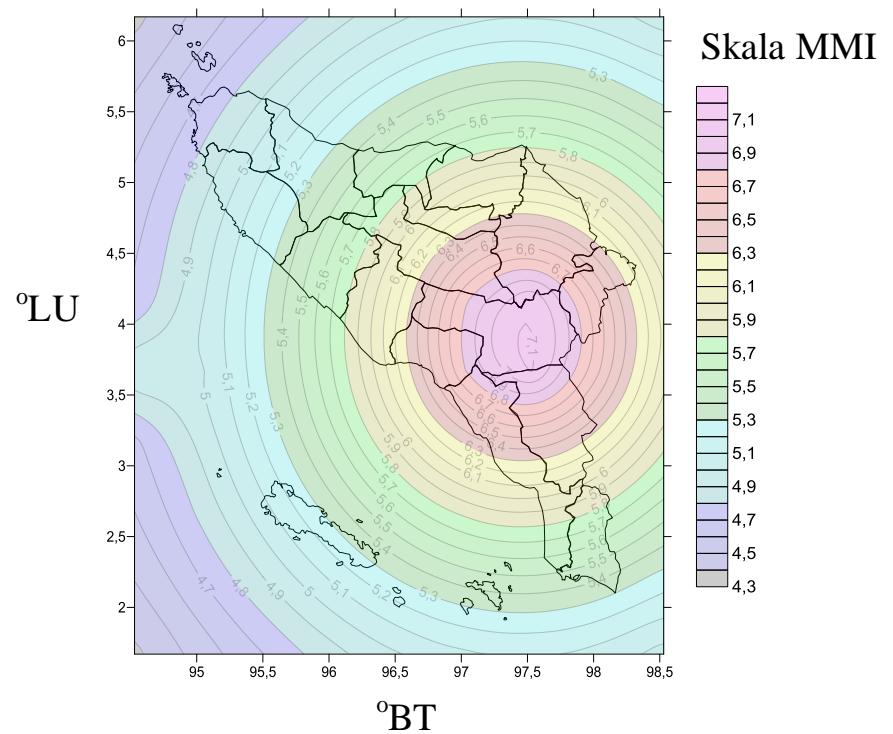

Gambar 3 Intensitas Gempa Provinsi Aceh dengan Episenter Segmen Tripa

\subsection{Diskusi}

Nilai percepatan tanah maksimum dengan episenter gempa segmen Tripa memiliki nilai yang berkisar antara $17 \mathrm{~cm} / \mathrm{s}^{2}$ sampai $112 \mathrm{~cm} / \mathrm{s}^{2}$. Nilai ini dipengaruhi oleh besarnya magnitudo gempa, kedalaman gempa, jarak gempa dan jarak hiposenter gempa ke titik penghitungan. Intensitas gempa berkisar antara III - V dengan gejala berupa gempa yang dapat dirasakan hingga kerusakan ringan.

Selain faktor-faktor yang telah disebutkan nilai percepatan tanah yang menyebabkan kerusakan juga disebabkan oleh kondisi geologi daerah tersebut. Bangunan yang berdiri di atas tanah dengan kondisi yang didominasi bebatuan memiliki ketahanan yang lebih dibandingkan dengan daerah sedikit bebatuan. Sehingga daerah yang rentan mengalami kerusakan adalah daerah yang paling dekat dengan sumber gempa dan kondisi dominan tanah saja.

\section{KESIMPULAN}

Berdasarkan gempa yang berasal dari segmen Tripa daerah yang memiliki nilai percepatan tanah terbesar adalah kabupaten Aceh Tenggara sebesar $112 \mathrm{~cm} / \mathrm{s}^{2}$. Sedangkan nilai percepatan tanah maksimum terkecil terdapat pada kabupaten Aceh Jaya sebesar $17 \mathrm{~cm} / \mathrm{s}^{2}$. Berdasarkan nilai intensitas gempa dengan episenter segmen Tripa memiliki skala III - VI MMI dengan gejala gempa yang dapat dirasakan hingga kerusakan ringan. 


\section{DAFTAR PUSTAKA}

Delfebriyadi, 2010, Rekayasa Gempa Teknik Sipil, CV.Ferila, Padang

Ibrahim, G. dan Subardjo., 2003, Buku Seismologi, BMKG, Jakarta.

Latief, H., 2003, Tsunami Assesment Around The Sunda Strait, Procceding of International Seminar / Workshop On Tsunami, Jakarta and Anyer, 26-29 August 2003.

Marlisa., Pujiastuti, D dan Billyanto, R., 2016, Analisis Percepatan Tanah Maksimum Wilayah Sumatera Barat (Studi Kasus Gempa Bumi 8 Maret 1977 dan 11 September 2014), Jurnal Fisika Unand Vol. 5, No. 1, Jurusan Fisika Unand.

Natawidjaja, D. H., 2007, Gempa Bumi dan Tsunami di Sumatera dan Upaya Untuk Mengembangkan Lingkungan Hidup Yang Aman Dari Bencana Alam, Laporan KHL, LIPI, Jakarta.

Sieh, K. and Natawidjaja, D., Neotectonics of the Sumatran Fault, Indonesia, Journal of Geophysical Research, 105 (B12) : 28,295 - 28,326, 2000.

Simanjuntak, B., 2014, Pengamatan Geofisika Dan Klimatologi, Buletin Stasiun Geofisika Klas 1 Padang Panjang, Nomor 1, BMKG, Hal 1-4.

Sunarjo, Gunawan, M. T., Pribadi, S., 2012, Gempa Bumi Edisi Populer, BMKG, Jakarta.

LIPI, 2010, Peta patahan aktif yang berpotensi gempa besar, http://www.scribd.com, diakses pada 10 November 2015 